\title{
ISCHAEMIA-MODIFIED ALBUMINM MEASURED AS A BIOMARKER IN EARLY DIAGNOSIS OF THE ACUTE CORONARY SYNDROME
}

\author{
Mohamed M Saker, Khaled A Elhefnawy, Mohamed El Sayed \& Mohamed S Fawzy* \\ Internal medicine and Medical Biochemistry* departments, Faculty of Medicine, Zagazig University.
}

ABSTRACT
BACKGROUND: An early identification of the patients with the Acute Coronary Syndrome (ACS) is of prime importance, due to the associated very high mortality. Only about $22 \%$ of the patients, who present at the emergency cardiology care centers with chest pain, have coronary disease. Ischemia modified albumin (IMA) is emerging as an exciting early marker of myocardial ischemia for diagnostic use in patients with suspected acute coronary syndrome (ACS). During an ischemic event, IMA concentrations in blood rise quickly above normal levels and remain elevated, returning to normal levels several hours after cessation of ischemia. IMA has recently been shown to be an early and sensitive marker of myocardial Ischemia. OBJECTIVE: The current study was to validate IMA or Albumin Cobalt Binding (ACB) assay when used together with standard markers of myocardial necrosis for the diagnosis and early detection of patients with ACS. METHODS: We enrolled 45 patients admitted to intensive cardiac care unit (ICCU) within 6 hours having acute chest pain and 15 healthy age and sex matched volunteers who didn't have any evidence of coronary artery disease to form the control group. The serum IMA level was estimated by the albumin cobalt binding test by using a digital spectrophotometer. At presentation serum IMA in conjunction with electrocardiogram (ECG) and cardiac enzymes Troponin I (cTnI) and CK-MB were evaluated. RESULTS: IMA levels were significantly higher in ischaemic patients compared to healthy controls. The sensitivity of IMA to detect ischaemia was $83.4 \%$ when IMA was combined with cTnI and CKMB, the sensitivity increased to 93\%. CONCLUSIONS: IMA has been found to be a highly sensitive, early diagnostic marker of acute chest pain and earlier rule out test in ACS patients. The combined use of IMA and cardiac troponin I enhances the sensitivity and specificity. Hence, a combination of IMA and cardiac troponin I can be used as a more precise diagnostic marker for ACS.

Key words: Acute coronary syndrome (ACS), Cardiac ischemia, Cardiac biomarkers, Ischemia modified albumin (IMA)

\section{INTRODUCTION}

A cute coronary syndrome (ACS) refers to a spectrum of clinical syndromes ranging from those for ST-segment elevation myocardial infarction (STEMI) to presentations found in nonST- segment elevation myocardial infarction (NSTEMI) or unstable angina. It is almost always associated with rupture of an atherosclerotic plaque with partial or complete thrombosis of the infarction related artery (1).

ACS is a sequence of pathophysiologic processes in coronary arteries, where inflammatory cytokines plays an important role causing plaque's destabilization and rupture, myocardial ischemia and infarction (2). A gold standard in diagnosis of the necrosis of myocardium is Troponin due to its high sensitivity and specificity. However, Troponins are not very early markers, and up to 4 hours from the onset of symptoms their sensitivity does not exceed 50\% [3].

Chest pain is a common presentation to the emergency department and accounts for approximately 5-10\% of all visits [4]. Most of these patients have relatively unremarkable electrocardiograms. The identification and diagnosis of ACS, including acute myocardial infarction (AMI), in these patients pose significant challenges. Rates of missed ACS among patients who present to the emergency department remain inappropriately high, ranging from 2 to $5 \%(5,6)$.

Assessment of the cardiac biomarkers levels (Myoglobin, CK-MB and Troponin) are one of the most essential and effective ways for detecting myocardial damage. The current conventional cardiac markers, CK-MB, Troponin (I) and (T) are sensitive and specific tests for the detection of myocardial necrosis, but they show a greater rise approximately 3-6 hours after the onset of the myocardial cell injury and thus, the patients may wait before they are diagnosed and treated; moreover, the usual biomarkers may not rise during reversible myocardial ischemia and other diagnostic tools such as stress testing, and echo cardiology are not routinely available (7). Recent efforts have focused on improving the accuracy of identifying patients with ACS who are at high risk of having an adverse event within the short term after assessment. During acute ischemia of 
myocardium, the ability of binding ions such as copper, zinc and cobalt is decreased, therefore a form of albumin is produced, which is described as ischemia modified albumin (IMA). In recent years, a number of studies have been conducted on the use of IMA in the diagnosis of ACS with variable results (8). Previous studies shown that IMA levels rises within minutes after cardiac ischemia. IMA is a serum albumin in which the $\mathrm{N}$-terminus has been chemically modified. The diagnostic albumin $\mathrm{CO}_{2}{ }^{+}$ binding (ACB) test for IMA is based on the observation that affinity of serum albumin for $\mathrm{CO}_{2}{ }^{+}$ is reduced after $\mathrm{N}$-terminus modifications (9). The amino terminal of plasma albumin normally has an affinity to cobalt, copper, and other heavy metal ions, and the N-terminal of albumin is modified during exposure to ischemic condition, due to the generation of oxidative free radicals and reactive oxygen species, resulting in the generation of IMA with a low binding affinity to heavy metals (10). Reports that IMA is increased within a few minutes after the onset of myocardial ischemia and continues to increase for $6-12 \mathrm{~h}$ suggest that it could be applied effectively to the detection of myocardial ischemic condition prior to the progression to myocardial necrosis (11).

Therefore, we measured IMA by applying the albumin cobalt binding (ACB) by Inverness Medical Innovations (Waltham, MA) to evaluate its usefulness as an early screening marker of ACS in patients having chest pain. In this indirect measurement method, a constant amount of cobalt is allowed to react with the patient serum and thus bind to albumin in the serum, and the remaining non-bound cobalt is measured (12). Therefore, it was anticipated that IMA would be influenced by the albumin concentration in the patients' blood, and that its clinical usefulness as a marker of ACS could be evaluated by designating the value that the measured IMA value of the patients was adjusted by the serum albumin concentration of the patients.

\section{PATIENTS AND METHODS \\ Patients' selection}

The current study was conducted in the Intensive Cardiac Care Unit (ICCU), of Zagazig University Hospital. The enrollment was between March 2012 and July 2012.

\section{Inclusion criteria:}

A total of 45 patients with age range of 38-67 years who admitted in the ICCU within 6 hours of acute chest pain were enrolled in the study (Group A). Fifteen age and sex matched healthy individuals' volunteers who didn't have any evidence of coronary artery disease were taken as the control group (Group B). Ethical formal consent from every patient was obtained after explanation the aim, benefits and the procedure of the work.

The patients were monitored and the diagnosis of ACS was confirmed as per the following criteria in compliance with the guidelines (13):

- Clinical symptoms or new ECG abnormalities are consistent with ischemia and one biomarker is elevated above the $99^{\text {th }}$ percentile of the upper reference limit.

- ST-segment elevation or presumed new LBBB is characterized by ST-segment $>0.5 \mathrm{~mm}$ elevation in 2 or more contiguous leads.

- Ischemic ST-segment depression > $0.5 \mathrm{~mm}$ $(0.05 \mathrm{mV})$ or dynamic $\mathrm{T}$ wave inversion with pain or discomfort. Non-persistent or transient STsegment elevation of $\geq 0.5 \mathrm{~mm}$ for $<20$ minutes.

- Imaging evidence of new loss of viable myocardium or new regional wall motion abnormality.

- Evidence of fresh thrombus by coronary angiography.

The data include a thorough history taking including (age, sex, duration of chest pain, and presence of risk factors for ACS as diabetes mellitus and hypertension), full physical examination, family history considering DM, hypertension and ischemic heart disease, serial 12-lead ECG and measurement of the cardiac markers.

\section{Exclusion criteria:}

A number of clinical conditions which could interfere with IMA levels were excluded:

chest pain duration for more than 24 hours, hypoalbuminemia, serum creatinine more than 3.0 $\mathrm{mg} / \mathrm{dl}$, patients with symptomatic peripheral vascular disease, patients with malignancy, patients with cerebrovascular strokes, patients with pulmonary embolism and patients with acute infections.

\section{Methods:}

All subjects included in the study were subjected to the following:

Routine biochemical and hematological profile: $\mathrm{CBC}$, liver function tests, fasting and 2 hours $\mathrm{pp}$ glucose level, blood urea and serum creatinine, lipid profile, and urine analysis. To identify any of the following; hypoalbuminemia, anemia, elevated liver enzymes, elevated s.creatinine, dyslipidemia and albuminuria. 
Assessment or measuring IMA by Albumin cobalt binding assay (ACB test)

IMA was measured by the ACB test on an automated biochemical instrument (Digital Spectrophotometer). Colorimetric detection of cobalt binding to albumin: this colorimetric method measures quantitatively the unbound cobalt remaining after cobalt-albumin binding has occurred with reduced cobalt-albumin cobalt bindings (14).

\section{Cardiac Enzymes}

A. Troponin: measured by (Quantitative detection of cardiac Troponin I (cTnI) by EISA.

B. CK-MB: The MB isozyme of Creatinine Kinas was measured by electrochemi luminescence immunoassay (ECLIA)

C. Lactate dehydrogenase (LDH): LDH was measured by colorimetric assay L-lactate substance.

\section{Statistical Analysis}

The results are presented as means \pm standard deviation or numbers and percentages. The data generated were analyzed with the help of computer statistical software packages namely EPI-INFO (ver 6.0) and SPSS (ver 16.0). The statistical significance of the differences between the study groups was assessed using student $t$-test (for parametric variables) The association of IMA and CK-MB levels with the clinical findings was compared by Chi-Square $\left(\chi^{2}\right)$ and ANOVA. The interrelationship of the variables was also assessed using Spearman's rank correlation coefficient. We adopted a $\mathrm{p}$ value of $<0.05$ as statistically significant.

\section{RESULTS:}

The baseline demographic and clinical characterizations of the patients and the healthy controls groups are given in Table (1). Sufficient data were available in 45 patients with ACS (36 men and 9 females, mean age $51.4 \pm 8.6$ years) and 15 healthy controls (11 men and 4 females, mean age $55 \pm 8.6$ years). Smoking was prevalent in $60 \%$ of cases followed by hypertension in $55.6 \%$ of cases. $48.9 \%$ of cases were diabetic, and ischemicECG was recorded in $82.2 \%$ of cases. Our finding showed that, there was no statistically significant difference between both groups regarding age and gender $(\mathrm{p}>0.05)$. There were statistically significant increase in hypertensives, smokers, and diabetics among studied groups $(\mathrm{p}<0.05)$. Also, there were statistically significant increases in ischemic-ECG changes in cases with ACS ( $p<$ $0.05)$.

The results of routine biochemical investigations are shown in Table (2). Our finding showed that, there was no statistically significant difference regarding liver and kidney parameters between the two studied groups $(\mathrm{p}<0.05)$. However, all lipid profile parameters were significantly higher in ACS patients compared with healthy control group $(\mathrm{p}<0.001)$.

The results of cardiac enzymes levels showed that ACS patients had higher CK-MB, Troponin I (cTnI) and LDH compared to the control group with highly significant difference $(\mathrm{p}<0.001)$. We also documented a significantly higher level of serum IMA in ACS patients compared to healthy controls, with a mean value of $95.7 \pm 15.2 \mathrm{U} / \mathrm{mL}$ (Table 3).

Clinical performance of IMA when analyzed alone as well as in combination with other biomarker was shown in Table 4. Our finding shows high sensitivity, high specificity, high PPV of IMA in ACS patients. On the other hand, the results show moderate sensitivity and specificity, with high positive predictive value (PPV) and low negative predictive value (NPV) of CK-MB in diagnosis of ACS patients. Our finding shows highly sensitivity, moderate specificity and high PPV and NPV of cTnI.

Serum IMA assays registered high sensitivity in comparison to CK-MB and cTnI whereas IMA in combination with $\mathrm{cTnI}$ or $\mathrm{CK}-\mathrm{MB}$ revealed better sensitivity as compared to combination of CK-MB and cTnI. When all these three markers were included together, the analysis showed the highest sensitivity with a high NPV in comparison to IMA alone or combined with either CK-MB or cTnI. However, its specificity remained low in comparison to CK-MB and cTnI when analyzed alone or in combination. The NPV of IMA also revealed high value in comparison to both CK-MB and cTnI and also in conjunction with these together. 
Table 1: Baseline characteristic and clinical data for subjects groups

\begin{tabular}{|c|c|c|c|c|}
\hline Variable & $\begin{array}{l}\text { Control } \\
(\mathbf{n}=15)\end{array}$ & $\begin{array}{c}\text { Cases } \\
(\mathrm{n}=45) \\
\end{array}$ & $T$ & P value \\
\hline $\begin{array}{r}\text { Age (years) } \\
\mathrm{X} \pm \mathrm{SD} \\
\text { Range } \\
\end{array}$ & $\begin{array}{c}55.0 \pm 8.6 \\
32-69 \\
\end{array}$ & $\begin{array}{c}51.4 \pm 8.6 \\
38-67 \\
\end{array}$ & $t=1.29$ & 0.19 \\
\hline $\begin{array}{ll}\text { Sex } & \\
& \text { Male } \\
& \text { Female }\end{array}$ & $\begin{array}{c}11(73.3 \%) \\
4(26.7 \%)\end{array}$ & $\begin{array}{c}36(80.0 \%) \\
9(20.0 \%)\end{array}$ & $\chi^{2}=0.03$ & 0.85 \\
\hline $\begin{array}{c}\text { Hypertension } \\
+ \text { ve } \\
- \text { ve }\end{array}$ & $\begin{array}{c}3(20.0 \%) \\
12(80.0 \%)\end{array}$ & $\begin{array}{l}25(55.6 \%) \\
20(44.4 \%)\end{array}$ & $\chi^{2}=5.71$ & $<0.016^{*}$ \\
\hline $\begin{array}{l}\text { DM } \\
+ \text { ve } \\
- \text { ve }\end{array}$ & $\begin{array}{c}3(20.0 \%) \\
12(80.0 \%)\end{array}$ & $\begin{array}{l}22(48.9 \%) \\
23(51.1 \%)\end{array}$ & $\chi^{2}=3.86$ & $<0.049^{*}$ \\
\hline $\begin{array}{c}\text { Smokers } \\
+ \text { ve } \\
- \text { ve }\end{array}$ & $\begin{array}{c}3(20.0 \%) \\
12(80.0 \%)\end{array}$ & $\begin{array}{l}27(60.0 \%) \\
18(40.0 \%)\end{array}$ & $\chi^{2}=7.2$ & $0.007^{*}$ \\
\hline $\begin{array}{l}\text { ECG } \\
\quad \begin{array}{l}\text { Normal } \\
\text { Ischemia }\end{array}\end{array}$ & $\begin{array}{c}15(100.0 \%) \\
0(0.0 \%)\end{array}$ & $\begin{array}{c}8(17.8 \%) \\
37(82.2 \%)\end{array}$ & $\chi^{2}=32.17$ & $0.001^{*}$ \\
\hline
\end{tabular}

DM: Diabetes mellitus

NS: No significant $(\mathrm{p}>0.05)$

ECG: Electrocardiography $\quad *$ : Significant $(\mathrm{p}<0.05)$

Table 2: Comparison of routine biochemical investigation in subjects groups

\begin{tabular}{|c|c|c|c|c|}
\hline Variable & $\begin{array}{l}\text { Control } \\
(\mathrm{n}=15)\end{array}$ & $\begin{array}{c}\text { Cases } \\
(n=45)\end{array}$ & $T$ & P value \\
\hline $\begin{array}{l}\text { S. Albumin }(\mathrm{mg} / \mathrm{dl}) \\
\text { X } \pm \text { SD } \\
\text { Range }\end{array}$ & $\begin{array}{r}4.8 \pm 0.7 \\
4.5-5.6\end{array}$ & $\begin{array}{c}4.2 \pm 0.4 \\
3.8-5.1\end{array}$ & 1.96 & 0.54 \\
\hline $\begin{array}{l}\text { Total protein }(\mathrm{mg} / \mathrm{dl}) \\
\mathrm{X} \pm \mathrm{SD} \\
\text { Range }\end{array}$ & $\begin{array}{c}7.8 \pm 8.6 \\
6.5-8.9 \\
\end{array}$ & $\begin{array}{c}7.1 \pm 0.46 \\
6-8.1 \\
\end{array}$ & 0.16 & 0.87 \\
\hline $\begin{array}{r}\text { SGPT (U/l) } \\
\text { X } \pm \text { SD } \\
\text { Range } \\
\end{array}$ & $\begin{array}{c}29.6 \pm 5.7 \\
18-37\end{array}$ & $\begin{array}{c}34.7 \pm 13.5 \\
21-65\end{array}$ & 1.42 & 0.15 \\
\hline $\begin{array}{r}\text { SGOT }(\mathrm{u} / \mathrm{l}) \\
\mathrm{X} \pm \mathrm{SD} \\
\text { Range } \\
\end{array}$ & $\begin{array}{c}25.6 \pm 5.5 \\
16-37 \\
\end{array}$ & $\begin{array}{c}30.6 \pm 13 \\
20-58 \\
\end{array}$ & 0.56 & 0.57 \\
\hline $\begin{array}{l}\text { Total bilirubin }(\mathrm{mg} / \mathrm{dl}) \\
\mathrm{X} \pm \mathrm{SD} \\
\text { Range }\end{array}$ & $\begin{array}{c}0.64 \pm 0.17 \\
0.72-1.15\end{array}$ & $\begin{array}{l}0.98 \pm 0.2 \\
0.87-1.7\end{array}$ & 0.11 & 0.91 \\
\hline $\begin{array}{c}\text { Creatinine }(\mathrm{mg} / \mathrm{dl}) \\
\mathrm{X} \pm \mathrm{SD} \\
\text { Range }\end{array}$ & $\begin{array}{c}0.76 \pm 0.2 \\
0.5-1.2\end{array}$ & $\begin{array}{c}0.7 \pm 0.14 \\
0.5-1\end{array}$ & 1.32 & 0.18 \\
\hline $\begin{array}{l}\text { Total cholesterol }(\mathrm{mg} / \mathrm{dl}) \\
\mathrm{X} \pm \mathrm{SD} \\
\text { Range }\end{array}$ & $\begin{array}{c}192.4 \pm 218 \\
167-220\end{array}$ & $\begin{array}{c}291 \pm 72 \\
17.5-430\end{array}$ & 5.17 & $<0.001^{*}$ \\
\hline $\begin{array}{l}\text { Triglyceride }(\mathrm{mg} / \mathrm{dl}) \\
\mathrm{X} \pm \mathrm{SD} \\
\text { Range }\end{array}$ & $\begin{array}{c}110.4 \pm 25.8 \\
77-145\end{array}$ & $\begin{array}{c}189.5 \pm 62.3 \\
90-310\end{array}$ & 4.7 & $<0.001^{*}$ \\
\hline $\begin{array}{c}\text { LDL (mg/dl) } \\
\text { X } \pm \text { SD } \\
\text { Range }\end{array}$ & $\begin{array}{c}98 \pm 32.3 \\
50-140\end{array}$ & $\begin{array}{c}203 \pm 51.2 \\
100-290\end{array}$ & 7.46 & $<0.001^{*}$ \\
\hline
\end{tabular}

SGPT or AST: aspartate aminotransferase SGOT or ALT: alanine aminotransferase

LDL: Low density of lipoprotein $\quad$ *: highly significant $(\mathrm{p}<0.001) \quad$ S: Significant $(\mathrm{p}<0.05)$ 
Table 3: Levels of cardiac enzymes (CK-MB, Troponin I, and LDH) and IMA on admission in the ACS and control group

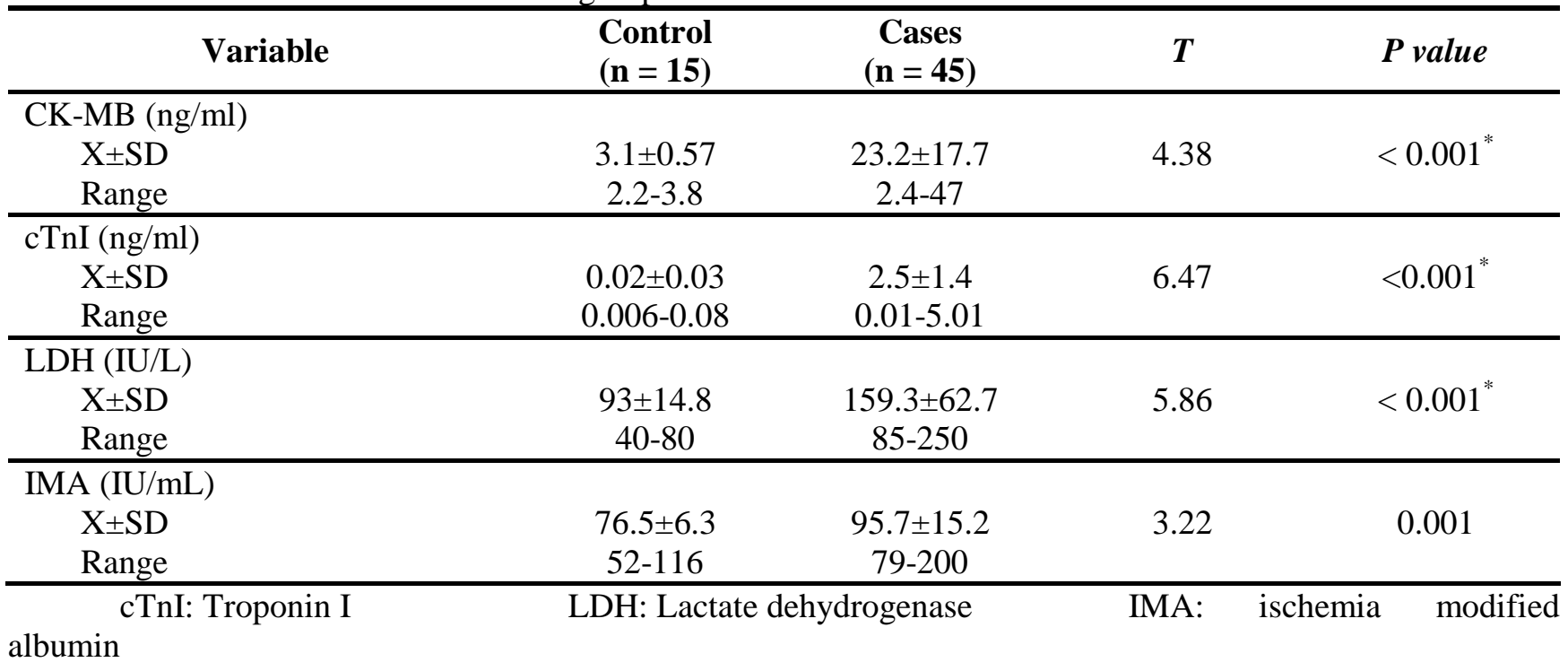

Table 4: Clinical performance of IMA alone and in combination subjects groups

\begin{tabular}{|c|c|c|c|c|}
\hline Test & Sensitivity (\%) & Specificity (\%) & PPV (\%) & $\overline{\text { NPV }(\%)}$ \\
\hline IMA & 83.4 & 87.5 & 90 & 72 \\
\hline CK-MB & 76.01 & 72.6 & 79.6 & 60.3 \\
\hline cTnI & 87.6 & 79.2 & 89 & 74 \\
\hline $\mathrm{IMA}+\mathrm{CK}-\mathrm{MB}$ & 86.5 & 85 & 89.2 & 78.4 \\
\hline $\mathrm{IMA}+\mathrm{cTnI}$ & 92.2 & 91.7 & 93 & 84 \\
\hline CK-MB + cTnI & 78 & 90 & 89 & 55 \\
\hline $\mathrm{IMA}+\mathrm{CK}-\mathrm{MB}+\mathrm{cTnI}$ & 93 & 63 & 74 & 91 \\
\hline
\end{tabular}

albumin

\section{DISCUSSION:}

Ischemia is a common under diagnosed vascular emergency, which is associated with an adverse prognosis. It is initiated whenever the arterial flow cannot supply sufficient oxygen resulting to irreversible damage and cell death. The clinical assessment is essential for the timely diagnosis and intervention of this disorder. Yet, no laboratory test for ischemia is available for the early diagnosis of this clinically challenging situation (15).

IMA is regarded as a new sensitive marker of myocardial ischemia, in contrast to cardiac enzymes which are released when cardiac necrosis occurs.
During an acute ischemic event, structural changes occur in the amino terminus of albumin, rapidly reducing its capacity to bind transition metal ions and generate a metabolic variant of the albumin referred as IMA (16). IMA was studied primarily as a diagnostic marker in selected populations with ACS. IMA measurements have demonstrated high sensitivity of detecting even sub-clinical myocardial ischemia and strong predictive power of subsequent cardiac troponin results in ACS patients (17).

The IMA measurement as a marker of myocardial ischemia without myocardial necrosis and/or preceding myocardial necrosis has introduced the hope for improved diagnosis in 
patients with ACS without or with non-specific ECG changes [18\&19]. The evaluation of patients presenting with chest pain or symptoms suggestive of cardiac ischemia remains a diagnostic challenge. These patients are often a heterogeneous group with varying risk factors for coronary artery disease. In many clinical settings, including the emergency department, the ability of a diagnostic test to rule out the diagnosis of ACS is important (20). However, IMA may increase in conditions of non cardiac ischemia, such as skeletal muscle, cerebral, pulmonary and gastrointestinal ischemia and in diseases which are potent producers of free radicals, such as liver cirrhosis, infections. Systemic sclerosis and advanced neoplasm. Therefore, the specificity of IMA concentrations alone in the detection of cardiac ischemia is quite limited $(21 \& 22)$.

Our study aimed to validate IMA or ACB assay when used together with standard markers of myocardial necrosis for the diagnosis and early detection of patients with ACS.

Again in cases with cardiac ischemia, it may be more difficult to reach at a diagnosis when the patient has acute chest pain with a non-diagnostic ECG and alteration in normal markers for necrosis. In such cases patients are at increased risk for subsequent coronary events but they may often be discharged because there is insufficient evidence to justify hospital admission (23).

The current study shows that IMA has a comparatively high specificity for prediction of a discharge diagnosis of ACS; we studied the value of IMA, either alone or in combination with other well-known cardiac biomarkers, namely CK-MB and cTnI, in the early diagnosis of ACS.

In our study, 45 cases were confirmed as ACS using follow-up test, the study confirmed the previously reported value of both CK-MB and cTnI as early biomarkers of ACS. The sensitivity, specificity, positive predictive value (PPV) and negative predictive value (NPV) of CK-MB for the diagnosis of ACS for patients with acute chest pain are $76 \%, 72.6 \%, 79.6 \%$ and $60.3 \%$ respectively.

The combination of IMA assay with either CKMB or cTnI increased the diagnostic validity of the test, compared to either test alone, with the highest sensitivity, specificity, PPV and NPV estimated for the combined IMA/cTnI assay $(92.2 \%, 91.7 \%, 93 \%$, and 84 respectively). IMA assay showed sensitivity, specificity, PPV, and NPV higher than those for CK-MB and compared to those for cTnI. These results are in a concordance with the result of a study, which evaluated IMA for the diagnosis of cardiac ischemia in 208 patients attending emergency department ; who concluded that, the diagnostic performance of the IMA level in the ACS patients was greater as compared to that of the cTnI assay (25). The sensitivity and the specificity of IMA were significantly greater than those of cTnI. The combination of the IMA and the cTnI results improved the sensitivity of the detection of ACS to $96 \%$ (26\& 27).

A higher specificity and sensitivity along with a higher positive and negative predictive value for IMA as compared to the CK-MB for the detection of ischemic heart condition reinforces the postulate that the two tests have different roles to play in the management of patients with ACS where IMA appears to establish itself as the marker for cardiac ischemia (20). Whereas CK-MB and cTnI should be used to follow up the cases with overt infraction, the sensitivity, specificity, PPV and NPV of cTnI for the diagnosis of ACS for patients with acute chest pain are $87.6 \%, 79.2 \%, 89 \%$ and $74 \%$ respectively (28). Furthermore, the sensitivity was additionally improved by adjusting the IMA measurement with the serum albumin of the patient. For the screening of ACS, the sensitivity and negative predictive value of IMA were higher than those of the conventional cardiac markers, CK-MB and cTnI, and its specificity was lower, which were similar to the results of previous studies (sensitivity, 80-90\%; negative prediction rate, $85-92 \%$; specificity, 31$49 \%$ ) (29). The increase of IMA sensitivity could be explained by its theoretical increase under ischemic condition prior to the development of tissue necrosis.

The findings of our work agree with several other publications that have evaluated the clinical utility of IMA in patients presenting to the Emergency Department (ED) with suspected ACS. Takshid et al, (28), enrolled 256 ACS patients at four centers and examined samples taken on admission and 6-24 hours later. All patients had a negative cardiac cTnI result at presentation and cTnI was used as the outcome measure. At the optimum cutoff point of 75 units $/ \mathrm{mL}$, the sensitivity and specificity of the ACB Test were $83 \%$ and $69 \%$, respectively. The negative predictive value was $96 \%$ and the positive predictive value was 33\%. Sinha et al, (30) also evaluated IMA for the diagnosis of cardiac ischemia in 208 patients attending the Emergency Department within 3 hours of the onset of chest pain. In this study, the final 
diagnosis was based on the history, clinical examination, serial cardiac cTnI results, and data from medical records. The sensitivity of IMA at presentation for an ischemic origin of chest pain was $82 \%$, the specificity was $46 \%$, the negative predictive value was $59 \%$, and the positive predictive value was $72 \%$. Furthermore, IMA had a higher sensitivity than the 12-lead ECG and initial cTnI levels for the diagnosis of ACS, whereas the combination of ECG, cTnI and IMA identified 95\% of patients whose chest pain was attributable to ischemic heart disease.

A prospective observational study assessing low risk patients with chest pain showed that the measurement of IMA and cTnI at presentation had high sensitivity rates $(97.6 \%)$ but markedly lowers (13.6\%) specificity rates (31).

A subsequent study of 538 patients admitted because of acute chest pain, evaluation unit found admission measurement of IMA plus cTnI-I had $100 \%$ sensitivity for prediction of a final diagnosis of acute MI (32).

A meta-analysis of current data has shown that when the IMA result is used alone it has a $91 \%$ negative predictive value for excluding ACS in the $\mathrm{ED}$, which increases to $97 \%$ when it is used in combination with negative cTnI measurements and a normal or non-diagnostic ECG (33).

However, as promising as the IMA assay appears, some degree of caution is still indicated. The currently accepted strength of IMA lies in its negative predictive value for excluding the presence of ischemia. Unfortunately, predictive values can't necessarily be translated into clinical practice; in reality, predictive value is less a measure of test performance than it is a reflection of disease prevalence in the population being tested (34).

In conclusion; this work confirms the previously reported value of IMA assay, especially when used in combination with negative troponin measurement and a normal or non-diagnostic ECG, for the evaluation of patients with acute chest pain or symptoms in ICCU, suggestive of cardiac ischemia. IMA has evaluated as highly sensitive, early diagnostic marker of acute chest pain and earlier rule out test in IMA patients. However, several novel biomarkers have the potential to improve the sensitivity of diagnosing ACS when combined with cardiac-specific troponin.

The prognostic significance of IMA needs further evaluation in large population and randomized studies before it can be used for risk stratification in patients with ACS.

\section{REFERENCES}

1. Gurm HS, Gore JM, Anderson FA Jr, et al. Comparison of Acute Coronary Syndrome in Patients Receiving Versus Not Receiving Chronic Dialysis (from the Global Registry of Acute Coronary Events [GRACE] Registry). Am J Cardio,( 2012); 109, (1):19-25.

2. O'Connor RE, Bossaert L, Arntz HR, Brooks SC, Diercks D, Feitosa-Filho G, et al. Part 9: acute coronary syndromes: 2010 International Consensus on Cardiopulmonary Resuscitation and Emergency Cardiovascular Care Science With Treatment Recommendations. Circulation, (2010); 122, (2):S422-65.

3. O'Riordan M. Negative Troponin and Copeptin Tests Rule Out Acute Coronary Syndrome. Medscape Medical News. European Society of Cardiology (ESC) Congress Sep (2013).

4. Owens PL, Barrett ML, Gibson TB, Andrews RM, Weinick RM, Mutter RL. Emergency department care in the United States: a profile of national data sources. Ann Emerg Med, (2010);56:150-65.

5. Pope JH, Aufderheide TP, Ruthazer R, et al. Missed diagnoses of acute cardiac ischemia in the emergency department. N Engl J Med, (2000); 342:1163-70.

6. Christenson J, Innes G, McKnight D, et al. Safety and efficiency of emergency department assessment of chest discomfort. CMAJ, (2004); 170:1803-7.

7. Kritsanee M, Titiporn M, Saowanee L, et al. Combinational determination of ischemia modified albumin and protein carbonyl in the diagnosis of non ST-elevation Myocardial Infarction. Indian Journal of Clinical Biochemistry. (2011); 26(4):389-95.

8. Peacock F, Morris DL, Anwaruddin S, Christenson RH, Collinson PO, Goodacre SW, et al. Meta-analysis of ischemia-modified albumin to rule out acute coronary syndromes in the emergency department. Am Heart J, (2006); 152: 253-262.

9. Pan S, Tong C, Lin Q, Yao C, Zhao J, Deng Z. Ischemia-modified albumin measured with ultra-filtration assay in early diagnosis of acute coronary syndrome. World Emerge Med. (2010); 1, (1):37-40.

10. Bhagavan NV, Lai EM, Rios PA, Yang J, Ortega-Lopez AM, Shinoda H, Honda SA, Rios 
$\mathrm{CN}$, Sugiyama CE, Ha CE. Evaluation of human serum albumin cobalt binding assay for the assessment of myocardial ischemia and myocardial infarction. Cline. Chem., (2003); 49:581-5.

11. Sbaroni E, Georgiadou P, Voudris V. Ischemia modified albumin changes-review and clinical implication (Cline Chem. Lab Med, (2011); 49(2), 177-184.

12. Bar-Or, D., Lau, E., Rao, N., Bampos, N. and Winkler, J.V. A novel assay for cobalt albumin binding and its potential as a marker for myocardial ischemia - a preliminary report, (2000); J. Emerge. Med. 19. 311-315.

13. Cooper A, Calvert N, Skinner J, Sawyer L, Sparrow K, Timmis A, et al. Chest pain of recent onset: assessment and diagnosis of recent onset chest pain or discomfort of suspected cardiac origin Clinical Guideline 95. London (2010); National Clinical Guideline Centre for Acute and Chronic Conditions;

14. Bar-Or D, Lau E, Winkler JV. Novel assay for cobalt-albumin binding and its potential as a marker for myocardial ischemia - a preliminary report. J Emerge Med (2000); 19: 311-15.

15. Libby P, Theroux P. Pathophysiology of coronary artery disease. Circulation (2005); 111:3481-8.

16. Dekker MS, Mosterd A, van't Hof AW, Hoes AW. Novel biochemical markers in suspected acute coronary syndrome: systematic review and critical appraisal. Heart (2010); 96:1001-10

17. Hjortshoj S, Kristensen SR, Ravkilde J. Diagnostic value of ischemia-modified albumin in patients with suspected acute coronary syndrome. Am J Emerge Med (2010); 28:170-76.

18. Collinson P, Gaze D, Bainbridge $K$, et al . Utility of admission cardiac Troponin and Ischemia modified albumin measurements for rapid evaluation and rule out of suspected acute myocardial infarction in the emergency department. Emerge Med J. (2006); 23:25661.

19. Anna Wudkowska, Jan Goch, Aleksander Goch. Ischemia modified albumin in differential diagnosis of acute coronary syndrome without ST elevation. Kardiol Pol, (2010); 68(4): 43137.

20. Anwaruddin S, Januzzi Jr JL, Baggish AL, Lewandrowski EL, Lewandrowski KB.
Ischemia-modified albumin improves the usefulness of standard cardiac biomarkers for the diagnosis of myocardial ischemia in the emergency department setting. Am J Clin Pathol, (2005); 123:140-5.

21. Fidan E, Mentese A, Kavgaci H, et al. Increased ischemia-modified albumin level in patients with gastric cancer, Neoplasm, (2012); 59:393397.

22. Gunduz A, Turkmen S, Turedi S, et al. Timedependent variations in ischemia-modified albumin levels in mesenteric ischemia. Acad Emerg Med, (2009); 16:539-43.

23. Lin RM, Fatovich DM, Grasko JM, Vasikaran SD. Ischaemia modified albumin cannot be used for rapid exclusion of acute coronary syndrome. Emerge Med J (2010); 27:668-71.

24. Rathore S, Knowles P, Mann AP, Dodds PA, Rathore S, Knowles P, et al. Is it safe to discharge patients from accident and emergency using a rapid point of care triple cardiac marker test to rule out acute coronary syndrome in low to intermediate risk patients presenting with chest pain? Euro J Intern Med (2008); 19:537-40

25. Sinha MK, Gaze DC, Tippins JR, Collinson PO, Kaski JC. Ischemia modified albumin is a sensitive marker of myocardial ischemia after percutaneous coronary intervention. Circulation (2003); 107(19):2403-05.

26. Chawla R, Goyal N, Calton R, et al;IMA A novel marker of ACS. Ind. J. Cline. Bio Chem.; (2006): 21(1):77-82.

27. Liyan C, Jie Z, Yonghua W, et al: Assay of IMA and CRP in the early diagnosis of ACS. Cline. Lab. Anal.; (2008): Vol.22, no. 1 pp. 45-49.

28. Takshid M, Kojuri, Tabei B, Tavasouli A, Heidary S, Tabanbeh M . Early Diagnosis of acute coronary syndrome with Sensitive Troponin I and Ischemia Modified Albumin. Iranian Cardiovascular Research Journal (2010); 4(4): 144-51.

29. Christenson RH, Duh SH, Sanhai WR, Wu AH, Holtman V, et al. Characteristics of an Albumin Cobalt Binding Test for assessment of acute coronary syndrome patients: A multicenter study. Cline Chem., (2001); 47(3):464-70.

30. Sinha MK, Gaze DC, Tippins JR, Collinson PO, Kaski JC. Ischemia modified albumin is a sensitive marker of myocardial ischemia after 
percutaneous coronary intervention.

Circulation, (2003); 107(19):2403-5.

31. Keating L, Benger JR, Beetham R, et al. The PRIMA study: presentation, Ischaemiamodified albumin in the emergency department. Emerge Med J, (2006); 23:764-8.

32.Collinson PO, Gaze DC, Bainbridge K, Morris F, Morris B, Price A, Goodacre S. Utility of admission cardiac troponin and "Ischemia Modified Albumin" measurements for rapid evaluation and rule out of suspected acute myocardial infarction in the emergency department. Emerge Med J, (2006); 23(4):256

33. Chawla R, Goyal N, Calton R, Goyal S. Ischemia modified albumin: A novel marker for acute coronary syndrome. Indian $\mathrm{J}$ Clin Biochem, (2006); 21, (1):77-82.

34. Sbarouni E, Georgiadou P, Kremastinos D, Voudris V. Ischemia Modified Albumin: Is This Marker of Ischemia Ready for Prime Time Use? Hellenic J Cardio (2008); 49: 26066. 